Indian Journal of Clinical Biochemistry, 2007 / 22 (2) 101-105

\title{
EFFECT OF SUPPLEMENTATION OF VITAMIN C AND E ON OXIDATIVE STRESS IN OSTEOPOROSIS
}

\author{
Sarita N. Chavan, Umesh More, Shruti Mulgund, Vishal Saxena and Alka N. Sontakke \\ Department Of Biochemistry, Pad. Dr. D.Y. Patil Medical College, Pimpri, Pune-18
}

\begin{abstract}
Osteoporosis encompasses a wide spectrum of conditions associated with imbalance of osteoclastic and osteoblastic activities. The increased activity of osteoclasts leads to increased free radical formation and hence lipid peroxidation. Present study probes into the role of antioxidants as a palliative treatment for osteoporosis. It involved 50 healthy controls and 75 clinically diagnosed osteoporosis patients. Both the groups underwent baseline assessment of biochemical markers viz. osteoblastic markers: serum Alkaline phosphatase, Free or ionic calcium and Inorganic phosphorus, osteoclastic markers: serum Tartarate resistant acid phosphatase and Malondialdehyde and the antioxidant status: serum Superoxide dismutase and Erythrocyte reduced glutathione. The osteoporotic group was then divided into groups A (Vitamin E- Evinal $400 \mathrm{mg}$ ), $B$ (Vitamin C-Celin $500 \mathrm{mg}$ ), C (Vitamin E+C-Evinal + Celin) for antioxidant supplementation for a period of 90 days. The results reveal that there is significant fall in concentration of serum MDA $(p<0.001), \operatorname{TrACP}(p<$ 0.01). Improvement in antioxidant status is reflected by significant rise in concentration of serum SOD ( $p<$ $0.001)$ and erythrocyte GSH $(p<0.001)$ after 90 days of antioxidant supplementation in osteoporosis. The findings indicate that on the whole bone status improved with prolonged antioxidant vitamin supplementation, which can be used as a palliative treatment for osteoporosis. The efficacy is not affected whether the vitamins are administered singly or conjointly.
\end{abstract}

\section{KEY WORDS}

Osteoporosis, Antioxidants, Lipid peroxidation

\section{INTRODUCTION}

Osteoporosis is the most common of all the metabolic bone disorders and is an important cause of morbidity in our country. The normal balance between bone formation and resorption is known as remodeling of the bone. It is a continuous process, which results in the maintenance of the skeletal mass. In osteoporosis, the bone mass is decreased, indicating that the rate of bone resorption must exceed that of bone formation. The difference is exaggerated by menopause (1) and longevity $(2,3)$. When peak adult bone mass is reached at about age 30-35 years, rates of bone formation and resorption are relatively low and approximately equal. The common causes

\section{Address for Correspondence:}

\section{Mrs Sarita Chavan}

Lecturer, Department of Biochemistry,

Pad. Dr. D.Y. Patil Medical College and Hospital,

Pimpri, Pune 18

E mailsnc_unc@yahoo.com include senile osteoporosis, alcoholism, malnutrition, immobilization, calcium deficiency and many metabolic disorders like Diabetes Mellitus and Hyperparathyroidism (4). The etiopathogenesis of osteoporosis is related to excessive free radicals formation (5). Free radicals are continuously produced in the body, mostly by biochemical redox reactions involving oxygen, which occur as part of normal cell metabolism. Free radicals are efficiently scavenged, but oxidative stress occurs when there is an imbalance between production and scavenging of the same, leading to oxidative deterioration of polyunsaturated fatty acids or lipids, thus compromising cellular function and antioxidant status of the body. As noted in the pilot study (6), with excessive free radicals, the osteoclastic activity and lipid peroxidation increases, as indicated by increase in the levels of Malondialdehyde (MDA). Apart from this, there is a diminution of the antioxidant status of the body, reflected by low levels of glutathione peroxidase (GHPx), glutathione reductase (GHR) and superoxide dismutase (SOD). 
The Osteoblastic markers Alkaline Phosphatase (ALP), Inorganic Phosphorus $(\mathrm{Pi})$ and Free or ionic calcium $\left(\mathrm{Ca}^{++}\right)$ also undergo alteration in the osteoporosis scenario (6). Vitamins $\mathrm{E}$ and $\mathrm{C}$ are antioxidant vitamins, which exert their osteoprotective effect (5) by curbing the excessive free radicals formation and thereby controlling the MDA levels, which indicate the lipid peroxidation in the body. The genesis of present study is the observation of hyperoxidant stress in osteoporosis as seen in the pilot study (6). It is to be seen, whether the antioxidant supplements help to alleviate the oxidative stress in the osteoporotic patients, and if so, their efficacy.

\section{MATERIALS AND METHODS}

The present study was carried out at Pad. Dr. D Y Patil Medical College, Hospital And Research Centre between the periods of October 2002 and September 2003. Seventy five clinically diagnosed osteoporotic patients (irrespective of etiology) attending the OPD and fifty healthy controls were enrolled in the study. All patients and control group individuals gave informed consent for the study. The control group individuals were in the age group of 20-50 years; were not suffering from any disease and were not on any medication before and during the study period. Smokers were excluded. The osteoporotic patients were in the age group between $45-70$ years. The subjects were divided into three groups of 25 patients each for administration of antioxidants for a period of 90 days. Group A - Vitamin E (Evinal 400 mg); Group B - Vitamin C (Celin 500 $\mathrm{mg}$ ) and Group C - Vitamin E + C (Celin + Evinal) Samples were collected and analyzed at 45 and 90 days.

Patients already on antioxidant supplementation or antiresorptive therapy, at the time of enrollment were excluded. Patients suffering from non-osteoid metabolic disorders like Diabetes Mellitus and Hyperparathyroidism were also excluded.

After overnight 12 hours fasting, basal sample $(10 \mathrm{ml}$ whole blood) was collected, under aseptic conditions, from both the control and study groups. Seven $\mathrm{ml}$ of it was collected in a plain sterile bulb for the estimation of ALP; Pi, SOD and MDA and $100 \mu \mathrm{L}$ serum was kept for the measurement of TrACP. Three $\mathrm{ml}$ of whole blood was collected anaerobically in a capped conical centrifuge tube for the free calcium estimation. One $\mathrm{ml}$ of whole blood was collected in the acid citrate dextrose $(A C D)$ bulb for the erythrocyte reduced glutathione estimation.

Samples were collected and analyzed for biochemical markers within 3 hours of sample collection by the following methodologies:

SOD by Marklund and Marklund (7), MDA Wilbur et al (8), ALP by kinetic method (9), Pi by Fiske Subbarrow (10), Tartarate resistant acid phosphatase (TrACP) by kinetic method (11), $\mathrm{Ca}^{++}$by ion selective electrode (12) and Erythrocyte reduced glutathione (GSH) by Beutler et al (13).

Statistical analysis was performed using ANOVA software, which involves paired and unpaired t-tests. Mean values and SD were calculated for every variable in each group and were compared between different groups. The 0.05 as point of minimal statistical significance.

\section{RESULTS AND DISCUSSION}

The baseline levels of osteoclastic markers namely serum MDA and TrACP are significantly increased in osteoporosis as compared with controls $(p<0.001, p<0.01)$. The baseline levels of osteoblastic marker ALP, are significantly raised $(p<$ 0.01 ) while there is no change in concentration of serum $\mathrm{Ca}^{++}$ and $\mathrm{Pi}$. The antioxidant marker i.e. serum SOD is significantly

Table I : Comparison of Biochemical markers between osteoporosis and control groups

\begin{tabular}{crr}
\hline Biochemical Parameters & Controls $(\mathrm{n}=50)$ & Osteoporosis $(\mathrm{n}=75)$ \\
\hline $\mathrm{ALP}(\mathrm{IU} / \mathrm{L})$ & $69.00 \pm 13.86$ & $78.00 \pm 22.00^{*}$ \\
Range & $55-83$ & $56-102$ \\
Median & 72.14 & 82.20 \\
$\mathrm{Ca}^{++}$(mmole / I) & $1.26 \pm 0.07$ & $1.27 \pm 0.09$ \\
Range & $0-2$ & $0-2$ \\
Median & 1.17 & 1.20 \\
$\mathrm{Pi}(\mathrm{mg} /$ dl) & $3.64 \pm 0.64$ & $3.60 \pm 1.11$ \\
Range & $3-5$ & $3-5$ \\
Median & 4.10 & 3.9 \\
$\mathrm{MDA}$ (nmole/ ml) & $3.40 \pm 1.44$ & $7.75 \pm 3.78^{* *}$ \\
Range & $2-5$ & $4-11$ \\
Median & 3.22 & 6.91 \\
$\mathrm{TrACP}(\mathrm{IU} / \mathrm{L})$ & $1.22 \pm 0.72$ & $1.68 \pm 1.09 *$ \\
Range & $0-2$ & $0-3$ \\
Median & 1.16 & 2.20 \\
$\mathrm{SOD}$ (units / ml) & $4.28 \pm 1.51$ & $3-7$ \\
Range & $3-6$ & 3.2 \\
Median & 4.34 & $8.68 \pm 2.87$ \\
$\mathrm{GSH}$ ( $\mu$ mole / gm of Hb) & $5.06 \pm 2.85$ & $5-12$ \\
Range & $5-11$ & 7.9 \\
Median & 7.50 & \\
\hline
\end{tabular}

Value are Mean $\pm S D,{ }^{*} p<0.01 ;{ }^{* *} p<0.001$ 
increased $(p<0.02)$ while no significant rise in concentration of erythrocyte GSH (Table I).

\section{Vitamin E Supplementation}

The osteoclastic markers i.e. serum MDA and TrACP showed significant decrease after 45 days and 90 days of antioxidant supplementation $(p<0.001, p<0.01)$. The osteoblastic markers serum ALP showed non significant decrease at 45 and 90 days but concentration of $\mathrm{Ca}^{++}$showed statistically significant decrease at 45 and 90 days $(p<0.001)$. No significant change was observed in serum phosphorus levels after 45 and 90 days of vitamin E supplementation (Table II).

\begin{tabular}{|c|c|c|c|}
\hline Biochemical Parameters & $\begin{array}{l}\text { Base line level } \\
\quad(n=25)\end{array}$ & $\begin{array}{l}45 \text { days } \\
(n=25)\end{array}$ & $\begin{array}{l}90 \text { days } \\
(n=25)\end{array}$ \\
\hline ALP (IU / L) & $79.00 \pm 12.18$ & $74.00 \pm 13.00$ & $70.00 \pm 14.00$ \\
\hline Range & $65-92$ & 61-88 & $64-85$ \\
\hline Median & 80.5 & 78.12 & 75.23 \\
\hline $\mathrm{Ca}^{++}($mmole / I $)$ & $1.27 \pm 0.05$ & $1.21 \pm 0.08^{\star *}$ & $1.17 \pm 0.07^{\star *}$ \\
\hline Range & $1-2$ & $0-2$ & $0-1.5$ \\
\hline Median & 1.22 & 1.18 & 0.98 \\
\hline $\mathrm{Pi}(\mathrm{mg} / \mathrm{dl})$ & $3.47 \pm 1.00$ & $3.40 \pm 0.59$ & $3.49 \pm 0.69$ \\
\hline Range & $2-5$ & $2-5$ & $2-5$ \\
\hline Median & 4.25 & 3.80 & 4.08 \\
\hline MDA (nmole/ ml) & $7.03 \pm 2.92$ & $5.72 \pm 2.41^{\star \star}$ & $4.60 \pm 2.19^{* *}$ \\
\hline Range & $4-10$ & $2-8$ & $1-7$ \\
\hline Median & 7.15 & 6.18 & 4.35 \\
\hline $\operatorname{TrACP}(\mathrm{IU} / \mathrm{L})$ & $1.67 \pm 1.28$ & $1.12 \pm 0.50$ * & $1.10 \pm 0.33^{*}$ \\
\hline Range & $0-3$ & $1-2$ & $0-2$ \\
\hline Median & 2.16 & 1.10 & 1.65 \\
\hline SOD (units / ml) & $4.66 \pm 1.35$ & $5.42 \pm 1.55^{\star}$ & $6.38 \pm 1.71^{* *}$ \\
\hline Range & $2-6$ & $3-7$ & $4-8$ \\
\hline Median & 5.24 & 5.10 & 5.7 \\
\hline GSH ( $\mu$ mole / gm of $\mathrm{Hb}$ ) & $9.23 \pm 2.53$ & $9.29 \pm 2.30$ & $9.74 \pm 2.21$ \\
\hline Range & $6-12$ & $6-12$ & $6-12$ \\
\hline Median & 8.60 & 8.0 & 7.81 \\
\hline
\end{tabular}

Value are Mean $\pm S D ;{ }^{*} p<0.01 ;{ }^{* *} p<0.001$

The antioxidant status of the body improved in terms of serum SOD concentration at 45 and 90 days $(p<0.001)$ and non significant change in erythrocyte GSH concentration.

\section{Vitamin C Supplementation}

The osteoclastic markers i.e. serum MDA and TrACP showed significant decrease after 45 days and 90 days of antioxidant supplementation $(p<0.001, p<0.001)$. The osteoblastic markers serum ALP showed significant decrease only at 90 days $(p<0.01)$ but concentration of $\mathrm{Ca}^{++}$showed statistically significant decrease at 45 and 90 days $(p<0.04)$. No significant
Table III : Comparison Of Biochemical markers before and after vitamin $\mathbf{C}$ supplementation in osteoporosis groups

\begin{tabular}{|c|c|c|c|}
\hline Biochemical Parameters & $\begin{array}{l}\text { Base line level } \\
\qquad(n=25)\end{array}$ & $\begin{array}{l}45 \text { days } \\
(n=25)\end{array}$ & $\begin{array}{l}90 \text { days } \\
(n=25)\end{array}$ \\
\hline ALP (IU / L) & $79.00 \pm 17.00$ & $72.00 \pm 16.00$ & $76.00 \pm 14.00^{* *}$ \\
\hline Range & $65-97$ & $56-88$ & $60-95$ \\
\hline Median & 82.04 & 74.54 & 79.40 \\
\hline $\mathrm{Ca}^{++}(\mathrm{mmole} / \mathrm{l})$ & $1.27 \pm 0.11$ & $1.20 \pm 0.09^{* *}$ & $1.19 \pm 0.17^{\star}$ \\
\hline Range & $1-2$ & $1-2$ & $1-2$ \\
\hline Median & 1.30 & 1.24 & 1.20 \\
\hline $\mathrm{Pi}(\mathrm{mg} / \mathrm{dl})$ & $3.48 \pm 1.10$ & $3.44 \pm 0.96$ & $3.32 \pm 0.92$ \\
\hline Range & $2-5$ & $3-4.5$ & 3- 5 \\
\hline Median & 4.10 & 3.65 & 3.39 \\
\hline MDA (nmole/ ml) & $8.66 \pm 4.62$ & $6.49 \pm 3.21^{\star *}$ & $5.63 \pm 2.81^{* *}$ \\
\hline Range & 3- 13 & 2- 10 & $2-8$ \\
\hline Median & 9.0 & 5.46 & 6.44 \\
\hline $\operatorname{TrACP}(\mathrm{IU} / \mathrm{L})$ & $1.79 \pm 0.91$ & $1.36 \pm 0.79$ ** & $1.15 \pm 0.69^{* *}$ \\
\hline Range & $0-3$ & $0-2.5$ & $1-2$ \\
\hline Median & 2.2 & 1.40 & 1.19 \\
\hline SOD (units / ml) & $4.54 \pm 1.30$ & $5.51 \pm 1.96^{* *}$ & $6.01 \pm 2.03^{* *}$ \\
\hline Range & $3-6$ & $3-7$ & $3-9$ \\
\hline Median & 4.18 & 6.24 & 7.50 \\
\hline GSH ( $\mu$ mole / gm of Hb) & $8.42 \pm 2.48$ & $9.10 \pm 2.69$ & $10.39 \pm 2.52^{* *}$ \\
\hline Range & $5-11$ & 6- 12 & $7.5-13$ \\
\hline Median & 8.90 & 9.64 & 9.80 \\
\hline
\end{tabular}

Value are Mean $\pm S D ;{ }^{*} p<0.01 ;{ }^{* *} p<0.001$

change was observed in serum phosphorus levels after 45 and 90 days of vitamin $\mathrm{C}$ supplementation (Table III).

The antioxidant status of the body improved in terms of serum SOD concentration at 45 days $(p<0.05)$ and at 90 days $(p<$ 0.001 ) also there is significant rise in erythrocyte $\mathrm{GSH}$ concentration at 90 days $(0.001)$.

\section{Vitamin E + C Supplementation}

The osteoclastic markers i.e. MDA showed significant decrease after 45 days and 90 days of antioxidant supplementation $(p<0.001)$. However activity of TrACP was not changed at 45 and 90 days. The osteoblastic markers ALP and Pi showed non significant decrease at 45 and 90 days but concentration of $\mathrm{Ca}^{++}$showed significant decrease at 90 days only $(p<0.01)$. The antioxidant status of the body improved in terms of significant rise $(p<0.001)$ in serum SOD concentration and erythrocyte GSH concentration at 90 days (Table IV).

The present study examined whether the antioxidant vitamin supplements could alleviate the adverse effects in the bone profile seen in osteoporosis. In Osteoporosis, which sets in because of longevity, menopause, smoking, alcoholism, 
Table IV : Comparison Of Biochemical markers before and after vitamin $E+C$ supplementation in osteoporosis groups

\begin{tabular}{|c|c|c|c|}
\hline Biochemical Parameters & $\begin{array}{l}\text { Base line level } \\
\qquad(n=25)\end{array}$ & $\begin{array}{l}45 \text { days } \\
(n=25)\end{array}$ & $\begin{array}{l}90 \text { days } \\
(n=25)\end{array}$ \\
\hline $\operatorname{ALP}(I U / L)$ & $79.00 \pm 17.00$ & $64.00 \pm 13.00$ & $77.50 \pm 12.00$ \\
\hline Range & $65-95$ & $51-77$ & 65- 90 \\
\hline Median & 83.50 & 69.10 & 80.05 \\
\hline $\mathrm{Ca}^{++}(\mathrm{mmole} / \mathrm{l})$ & $1.26 \pm 0.10$ & $1.24 \pm 0.08$ & $1.19 \pm 0.09^{*}$ \\
\hline Range & $1-2$ & $1-2$ & $1-2$ \\
\hline Median & 1.28 & 1.25 & 1.20 \\
\hline $\mathrm{Pi}(\mathrm{mg} / \mathrm{dl})$ & $3.86 \pm 1.23$ & $3.47 \pm 0.89$ & $3.52 \pm 0.72$ \\
\hline Range & $2-5$ & $2-5$ & $2.5-5$ \\
\hline Median & 4.20 & 3.94 & 4.45 \\
\hline MDA (nmole/ ml) & $7.44 \pm 3.43$ & $5.35 \pm 2.30^{* *}$ & $4.69 \pm 2.56^{* *}$ \\
\hline Range & $3-11$ & $2.5-8$ & $1-7$ \\
\hline Median & 7.90 & 6.06 & 5.42 \\
\hline $\operatorname{TrACP}(\mathrm{IU} / \mathrm{L})$ & $1.55 \pm 1.09$ & $1.33 \pm 0.56$ & $1.39 \pm 0.73$ \\
\hline Range & $0-3$ & $0-2$ & $0-2$ \\
\hline Median & 2.30 & 1.54 & 1.45 \\
\hline SOD (units / ml) & $5.61 \pm 1.88$ & $6.53 \pm 2.07$ & $7.77 \pm 2.06^{* *}$ \\
\hline Range & $3-7$ & $3-9$ & $4-10$ \\
\hline Median & 6.22 & 7.20 & 8.20 \\
\hline GSH $(\mu$ mole / gm of Hb) & $8.43 \pm 3.55$ & $9.81 \pm 3.59^{*}$ & $11.39 \pm 2.99^{* *}$ \\
\hline Range & $4-12$ & $6-13$ & $8-14$ \\
\hline Median & 8.80 & 10.22 & 10.41 \\
\hline
\end{tabular}

Value are Mean $\pm S D ;{ }^{*} p<0.01 ;{ }^{* *} p<0.001$

malnutrition, immobilization, calcium deficiency and many nonosteoid disorders, there is excessive osteoclastic activity in the bone, resulting in increased free radicals formation and hence, enhanced lipid peroxidation, culminating in imbalance between bone formation and resorption and adverse alteration in the normal bone remodeling (14-16). This picture is reflected by higher levels of MDA, osteoclastic marker i.e. TrACP and osteoblastic markers (ALP) and raised serum SOD levels in the osteoporotic patients as compared to control group.

The rise in serum MDA in osteoporosis may be because of overwhelming osteoclastic activity due to activation of osteoclasts. One important component is generation of superoxide radical (17). Normally this molecule is responsible for bone remodeling (18), when produced in excess it leads to oxidative stress if not metabolized by Superoxide dismutase i.e. SOD (19). This study reveals no change in erythrocyte GSH concentration that may explain rise in serum MDA levels is occurring due to increased lipid peroxidation inspite of raised serum SOD levels.

The other osteoclastic marker TrACP showed significant fall at 45 and 90 days of vitamin $E$ and $C$ supplementation individually. $\mathrm{Ca}^{++}$also showed fall that indicates mineralisation is occurring, as there is balance between osteoclastic and osteoblastic activities.

The significant rise in serum SOD and erythrocyte GSH after supplementation of vitamins $C$ individually and conjointly $E+$ $\mathrm{C}$ at 90 days indicates an improvement in the antioxidant status of the body.

Vitamin E exerts its antioxidant property by preventing chain propagation as a result of its ability to transfer phenolic hydrogen to a peroxyl free radical of a peroxidized polyunsaturated fatty acid, minimizing the lipid peroxidation. The major portion of peroxytocopherol so formed, is reconverted to tocopherol by vitamin $\mathrm{C}$ and small amount is excreted as such in the bile (5).

Vitamin $\mathrm{C}$ acts as water a soluble antioxidant by inhibiting initiation of lipid peroxidation It also acts as a cofactor for NADP reductase required for glutathione metabolism $(2,16)$.

The combined regimen of vitamin $E$ and $C$ does not seem to more effective compared to individual vitamin supplementation because of less availability of vitamin $C$ in the osteoclasts, in response to its shunting for the recycling of vitamin $E$, in reconverting peroxytocopherol to tocopherol.

Thus the present study suggests that prolonged antioxidant vitamin supplementation may be beneficial in treatment of osteoporosis with no change in the efficacy of antioxidant vitamin ( $E$ and $C$ ) supplementation whether administered individually or conjointly.

\section{ACKNOWLEDGEMENT}

Authors acknowledge financial support received from ICMR and facility provided by Dept. of Obstetrics \& Gynecology.

\section{REFERENCES}

1. Heaney RP, Rehecher RR et al. Menopausal changes in bone remodeling. J Lab Clin Med 1978; 92: 964-5.

2. Halliwel B and Gulteridge JMC. Lipid peroxidation, oxygen radicals, cell damage and antioxidant therapy. Lancet 1984; i : 1396-8.

3. Nohl $\mathrm{H}$. Involvement of free radicals in ageing: a consequence or cause of senescence. Br Med Bull 1993; 49: 653-67.

4. Andrew E, Rosenberg MD. Skeletal system and soft tissue tumors in: Cotran RS, Kumar V, Robbins S L and Schoen FJ, editors. Pathologic Basis of Disease, $5^{\text {th }}$ Ed. W B Saunders Co. Philadelphia, USA 1994:1220-21. 
5. Muray RK, Keeley F W. Structure and function of lipid soluble vitamins. In: Murray RK, Granner DK, Mayes PA, Rodwell VW, Harper's biochemistry, $25^{\text {th }}$ ed 57; Lange medical Books, Stamford, Connecticut Mc Graw hill 2000: 648-50

6. Sontakke AN, Tare RS. A duality in the roles of reactive oxygen species with respect to bone metabolism. Clin Chim Acta 2002; 318: 145-8.

7. Marklund S, Marklund G. A simple assay for superoxide dismutase using auto oxidation of pyrogallol. Eur $\mathrm{J}$ Biochem1974; 47: 469-72.

8. Wilbur KM, Bernheim F, Shapiro OW. The thiobarbituric acid method for malondialdehyde estimation. Arch Biochem Biophys1943; 250: 305-13.

9. Burtis and Ashwood. Teitz textbook of Clinical Chemistry, $3^{\text {rd }}$ ed. W.B. Saunders Co Philadelphia PA 1999;1351-52.

10. Fiske $\mathrm{CH}$, Subarrow Y. Harold Varely's. Practical Clinical biochemistry, $4^{\text {th }}$ ed. Delhi, India: CBS Publishers and Distributors1975; 446-7.

11. Kaplan LA, Pesce AJ. Clinical Chem.; Theory and analysis and correlation, $4^{\text {th }}$ ed. C.V. Mosky co. St. Louis $1984 ; 1087$.

12. Bowers GN, Jr Brassad C, Sena SF. Measurement of ionized calcium levels in serum with ion selective electrodes. A mature technology that can meet the daily service needs. Clini Chem 1986; 32 : 1437-44.
13. Burtis and Ashwood. Teitz text Book of Clinical Chemistry, $3^{\text {rd }}$ ed W.B. Saunders Co Philadelphia PA 1999 : 1652-3.

14. Korachich GB, Mishra OP. Lipid peroxidation in rat brain cortical slices as measured by TBA test. J. Neurochem1980; 35: 1449-52.

15. Murray RK, Keeley FW. The extracellular matrix: osteoporosis. In: Murray RK, Granner DK, Mayes PA, Rodwell VW, Harper's biochemistry, $25^{\text {th }}$ ed; 57 Lange medical Books, Stamford, Connecticut: McGraw Hill 2000; 710-11.

16. Raisz LG. The osteoporosis revolution. Ann Intern Med 1997;126: 458-62.

17. Yang S, Ries WL, Key Jr. NADP oxidase in the formation of superoxide in osteoclasts. Calcific Tissue Int 1998; 63: 34650

18. Victoria L Contie. The sculpting of bone; NCRR Reporter Remodelling Cover story 2000: 1-4.

19. Latscha B, Witkosarsat V. Oxidative stress in CRF and hemodialysis 2003; 297; 377-9. 